\title{
Perspectives on efficiency in transportation
}

David Levinson *

Department of Civil Engineering, University of Minnesota, 500 Pillsbury Drive SE, Minneapolis, MN 55455, USA

Received 4 December 2002; received in revised form 31 December 2003; accepted 5 January 2004

\section{Introduction}

The evaluation of transportation systems garners significant attention in the planning, engineering, policy, management, and economics literatures (Kaplan and Norton, 1996; Caltrans, 1998; Pickrell, 1999). Measures of effectiveness (MOE) include assessments of the efficiency of the system, as well as its equity or fairness, its effects on the environment, and the qualitative experience that users enjoy. This paper addresses efficiency measures put forth by different analysts. Each profession approaches the problem differently, with unique concerns and objectives. While each field adopts what it feels are appropriate, none of the current measures corresponds directly with the perceptions of transportation users, the perspective of the consumer. As shorthand, we can develop a chart to consider several of those

\footnotetext{
${ }^{*}$ Tel.: +1-612-625-6354.

E-mail address: levin031@tc.umn.edu (D. Levinson).
}

perspectives on efficiency:

\begin{tabular}{ll}
\hline Perspective & Profession \\
\hline Mobility and Safety & Engineers \\
Utility (Consumers' Sur- & Economists \\
plus) & \\
Productivity & Managers \\
Accessibility & Planners \\
\hline
\end{tabular}

The reasons for the different measures are that their 35 uses vary: planning, investment, regulation, design, 36 operations, management, and assessment are among the 37 aims. Where the traveler fits is not immediately clear, as 38 each profession asserts that it is primarily concerned 39 with the public interest.

Engineering textbooks say "The challenge of the 41 transportation engineering profession is to assist society 42 in selecting the appropriate transportation system con- 43 sistent with its economic development, resources, and 44 goals, and to construct and manage the system in a safe 45 and efficient manner" (Garber and Hoel, 1999, p. 13). 46 While including economic criteria, the text proposes 47 multiple criteria for evaluation. In general, engineers 48 focus on maximizing mobility (the speed and capacity of 49 the system) and safety, subject to cost constraints, as the 50 
51 other perspectives are out of their control, but tend to 52 concentrate on parts of the network rather than the trip 53 as a whole.

54 A planning textbook says "Urban planners and 55 scholars have long argued that the ease with which 56 people can reach employment locations, retail and ser57 vice outlets, and recreational opportunities should be 58 considered in any assessment of the health of a city. 59 They have implied that accessibility should be a central 60 part of any measure of quality of life (see e.g., Chapin, 61 1974; Wachs and Kumagai, 1973)." (Hanson, 1995, p. 62 5). Planners looking at the longer term consider the 63 location of places with respect to each other in the 64 accessibility measure, which traveler's consider in real 65 estate decisions.

66 A transportation economics text discussing project 67 evaluation states "The starting point for measuring 68 costs and benefits is willingness to pay: the amount of 69 money each individual would be willing to pay for the 70 change in his or her circumstances. ... Therefore will71 ingness to pay for a price reduction is correctly mea72 sured by the change in consumers' surplus, which is the 73 area under the demand curve and above a horizontal 74 line indicating the current price." (Small, 1999). Econ75 omists measure utility (or consumer's surplus), in the 76 hope of having incorporated traveler's preferences, and 77 try to ensure that benefits exceed costs, but admit that 78 utility cannot be completely measured.

79 Managers try to keep costs down and maintain the 80 productivity of the system. Novack, Rinehard, and 81 Langley (cited in Coyle et al., 2000, p. 15) conducted a 82 survey of logistics executives. "Changes in logistics 83 productivity do not result in reactions from customers 84 ... Productivity improvements in logistics are important 85 to internal customers, however, namely upper manage86 ment".

87 In addition to these efficiency aims, the political sys88 tem is also concerned with fairness and justice, which are 89 very difficult to define, while striving to guarantee that 90 public facilities are adequate or that an overall level of 91 service standard is met (Levinson, 2002). The profes92 sions generally take the "objective" viewpoint of the 93 omniscient central planner (who may in fact be an 94 engineer, manager, or economist) rather than the 95 "subjective" perspective of the travel consumer.

96 These perspectives often have implicit within them a 97 spatial dimension, the area or network elements that will 98 be considered in the analysis. Broadly, we can think of a 99 hierarchy of geographical units. The individual link 100 (road segment) can be aggregated in one of two ways, by 101 area into a subnetwork, or by path (route) into a trip. 102 All links comprise the network, which is a collection of 103 subnetworks. Each trip also uses a set of links between 104 an origin and destination. The spatial aggregation 105 dimension needs to be considered along with the various 106 perspectives, as improving one component (say a link) may do little good for other components (other links, 107 specific trips, or the network as a whole), and may 108 sometimes worsen them.

We also need to distinguish between the normative 110 (what should be) and the positive (what is) when con- 111 sidering efficiency measures. For each measure, we need 112 to define a scale across which values are compared. To 113 say that the speed on a link is $50 \mathrm{~km} / \mathrm{h}$ tells us nothing 114 about whether that is good or bad, it simply is. By 115 comparing the measured speed of $50 \mathrm{~km} / \mathrm{h}$ to a norma- 116 tive standard (for instance, a speed limit), we can then 117 determine whether we have a speeding problem (the 118 speed limit is $30 \mathrm{~km} / \mathrm{h}$ ), a congestion problem (the speed 119 limit is $110 \mathrm{~km} / \mathrm{h}$ ), or no problem.

Several attributes help define good MOE. While this list is by no means definitive, it may help in selecting MOEs.

(1) Different measures (e.g. transit and auto level of service) should be collectively complete in that one could combine them to attain an overall measure.

(2) Each measure should scale or aggregate well (e.g. it should be possible to combine measures of auto level of service measured on separate links or for separate trips).

124

3) Each measure should allow for disaggregation and analysis of components (e.g. it should be possible to take a measure of transit level of service measured for the system and disassemble that measure to obtain measures of components of the system).

(4) The measure should align with user experience and be understood by those users.

(5) The performance indicator must be measurable, or calculable from available (observable) data.

(6) The measure should be predictable, or able to be forecast.

(7) It must be useful in a regulatory or control context (so that the measure can be used to allow or restrict new development to maintain standards, or to help guide operational traffic engineering decision).

This paper considers the engineer's, economist's, 146 manager's, and planner's perspectives on efficiency for 147 transportation respectively. This paper examines the 148 measures used in each perspective and weighs their 149 advantages and disadvantages for various purposes. It 150 then applies each of the measures to the case of the Twin 151 Cities Ramp Meter shutdown, which took place in 2000152 (the details of the study can be found in Levinson et al., 153 2004). While the measures might not align exactly with 154 each profession's current practice, it is hoped that this 155 shorthand will provide insight into the problem of how 156 different measures are, and can be, used. The first section 157 summarizes various measures of mobility that are used 158 to assess transportation. This is followed by an exposi- 159 tion of transportation consumer surplus. Similar treat- 160 
161 ments of accessibility and productivity are provided. A 162 discussion of the traveler's perspective is then provided. 163 The conclusions call for broadening evaluation beyond 164 efficiency and into equity and for taking the subjective 165 point of view of the traveler rather than the "objective" 166 point of view of the omniscient planner/engineer/econ167 omist/manager.

\section{Mobility}

\subsection{Definition}

Handy (2002) notes, "The terms 'accessibility' and 'mobility' are often used together in transportation plans but without clear distinction." In brief, mobility measures describe the ease with which elements of the transportation system, or the transportation system as a whole can be used-how the network facilitates movement. However mobility measures do not weight the ease of movement by the number of places that can be reached, which is incorporated in accessibility measures described in a later section.

The Highway Capacity Manual (HCM) (TRB, 2000) distinguishes transportation facilities by type; highways are divided into interrupted and uninterrupted facilities. The HCM is a document designed by a committee, as illustrated in its multiplicity of measures for different facility types. For basic freeway segments, density is preferred to speed measures because speed is relatively invariant to traffic flow until volume is very close to capacity. Level of service ranges from A to F, level of service $\mathrm{E}$ is the critical density, that is the density at which capacity is reached.

The perspective offered in the Highway Capacity Manual, however, only measures mobility on individual network elements, not trips, subnetworks, or the network as a whole. The Texas Transportation Institute (TTI) has developed a methodology to compare con- gestion between urban areas (Texas Transportation 196 Institute, 2000). For metropolitan areas, TTI estimates 197 travel speed, travel delay, system travel speed, travel rate 198 index, fuel economy, wasted fuel, and congestion cost 199 among other measures. Travel delays are classified into 200 recurring and incident delays.The data used for TTI 201 analysis are obtained from the US DOT's Highway 202 Performance Monitoring System (HPMS), which com- 203 piles information on roadway systems maintained by 204 state and local agencies, as well as from local planning, 205 transportation agencies, and state DOTs. 206

Automobile measures of mobility (or level of service) 207 can be classified by at least two criteria. The first is scale 208 of analysis; for instance intersection approach, total 209 intersection, road segment, or a road network can all be 210 the basis for measurement. The second is kind of mea- 211 surement-volume or time. Table 1 arrays some mea- 212 sures by this scheme. Other automobile level of service 213 measures include: parking availability and cost, network 214 connectivity, conflict with non-auto system (e.g. pedes- 215 trian crossings), hazard rating, service station avail- 216 ability, ride comfort, aesthetics, and traveler 217 information (knowledge of expected delay). 218

In general, volume is easier to measure, as it requires 219 less tracking than delay, and is easier to accurately 220 predict, as delay depends on more factors (including 221 signal timings and cross-traffic). Similarly, the intersec- 222 tion approach is the most detailed level of analysis, and 223 is how travelers subjectively perceive the intersection. 224 However, from a broader perspective, there is some 225 desire to aggregate the measures (after all, trips occur on 226 multiple segments, and the success of the system de- 227 pends on more than one component). This suggests that 228 all three levels of detail (network, link, intersection) may 229 need to be assessed.

Commuters do not directly perceive volume-to- 231 capacity ratios and may only have a sense of traffic 232 density. But they do perceive travel time. Delay lends 233 itself more easily to a trip measure than does capacity. 234

Table 1

Some roadway mobility measures

\begin{tabular}{lll}
\hline Scale & Delay measures & Capacity measure \\
\hline Intersection approach & Stopped delay & Volume to capacity ratio \\
& & Queueing \\
Intersection & Average stopped delay & Critical lane volume: (CLV) \\
Road segment & Average delay (Actual time - Freeflow time) & Density \\
& Average travel speed & Volume to capacity ratio \\
Road network & Average travel speed & Cordon volume/cordon capacity \\
& Average percent delay & Screenline volume/screenline capacity \\
& Average trip time & Average congestion index: the (weighted) average \\
& Shoulder hour index (shoulder hour time/ & volume to capacity ratio for an area's links \\
& peak hour time) & CLVerage of area intersection: the (weighted) average of \\
& Percent of trips with delay $>X$ & The percent of links at each LOS
\end{tabular}


Table 2

Some non-auto system mobility measures

\begin{tabular}{lll}
\hline Stage & Time & Volume and capacity \\
\hline Walk (bike) and walk access and egress to & Walk travel time & Sidewalks/roadways (bikeway/roadway) \\
transit & Circuity & Connectivity \\
& Delay & Hazard \\
& Aesthetic & Bicycle parking \\
Auto access and egress & Auto access travel time & Parking availability and cost \\
Waiting & Waiting time (frequency) & Waiting comfort \\
& Reliability & \\
Transit in-vehicle & Travel time & Use \\
& Circuity & Comfort of service \\
\hline
\end{tabular}

235 This is because delay can be aggregated over an area or 236 trip. A trip-based delay measure would consider both 237 intersections and links implicitly; no distinction would 238 be made as to whether delay was caused by an inter239 section or a link. A volume-based measure would have 240 difficulty incorporating this. ${ }^{1}$

241 While transportation engineers most often deal with 242 automobile travel, the mobility and safety of non-auto travel should also be considered. The Bureau of Transportation Statistics (1999) reports that the automobile currently serves some $89.5 \%$ of daily trips in the United States. However, large segments of the population cannot drive an automobile for their transportation needs. Foremost are children under the age of 15 , which the census estimates at $21.3 \%$ of the population. The quality of their transportation depends in large part upon many microscale site planning design issues such as the provision of sidewalks, the location of paths and trails, building setbacks, and neighborhood road design which minimizes vehicular speed. Table 2 lists non-auto mobility measures.

\subsection{Application}

To compare the various classes of measures, we apply them to the same case, the eight-week shut off of Ramp Meters in 2000. Applying some of the mobility to evaluate ramp meters requires measurements at on-ramps, freeway segments and the system as a whole. Total delay, number of vehicles being delayed, average delay through the whole observation period, and average delay of each time interval are computed for each ramp. The travel time and delay for each freeway segment are measured. They are combined through synchronization into a series of OD matrices containing different mobility measures (travel time, travel delay, speed). The

\footnotetext{
${ }^{1}$ Several measures at the trip, subnetwork, or network level are weighted averages. Different weights can be taken, including vehicle kilometers traveled, vehicle hours traveled, link volumes, trips from a zone, or the number of observations (links, zones).
}

Table 3

Mobility measures with and without meters

\begin{tabular}{lllcl}
\hline & & $\begin{array}{l}\text { Travel } \\
\text { speed } \\
(\mathrm{km} / \mathrm{h})\end{array}$ & $\begin{array}{l}\text { Travel } \\
\text { time } \\
(\mathrm{s} / \mathrm{km})\end{array}$ & $\begin{array}{l}\text { Travel } \\
\text { delay } \\
(\mathrm{s} / \mathrm{km})\end{array}$ \\
\hline With meters & TH169 & 62 & 99 & 68 \\
& I-94 & 79 & 89 & 42 \\
Without & TH169 & 37 & 113 & 82 \\
meters & $\mathrm{I}-94$ & 87 & 75 & 28 \\
\hline
\end{tabular}

results for two roadways (Trunk Highway 169 north- 269 bound between I-494 and I-694, a suburban freeway, 270 and I-94 between downtown Minneapolis and down- 271 town St. Paul) are shown in Table 3.

Previous research indicates that ramp meters increase 273 the mobility of freeway networks. On TH-169, with 274 ramp metering, the average travel speed (taking ramp 275 delay into account) of the network increases from 37 to 276 $62 \mathrm{~km} / \mathrm{h}$; travel delay per $\mathrm{km}$ decreases from 82 to $68 \mathrm{~s} 277$ and the average travel time for one trip decreased from 278 610 to 330 s. However, on I-94, the network mobility 279 measures decrease slightly as the result of the ramp 280 meter control. The average travel speed (taking ramp 281 delay into account) of the network decreases from 87282 $\mathrm{km} / \mathrm{h}$ (without control) to $79 \mathrm{~km} / \mathrm{h}$ (with control). Travel 283 delay per mile increases from $27.9 \mathrm{~s}$ (without control) to 284 $42.1 \mathrm{~s}$ (with control) and the average travel time for one 285 trip increases from $285 \mathrm{~s}$ (without control) to $299 \mathrm{~s}$ (with 286 control).

\section{Utility}

\subsection{Definition}

The economist's perspective on efficiency revolves 290 around the notion of benefit/cost analysis. Benefits to 291 users in public projects can be measured as the sum of 292 the utility accruing to consumers. However, because, 293 
294 strictly speaking, utility is not measurable, consumers' 295 surplus is often used. Consumers' surplus is the differ296 ence between what individuals would pay and what they 297 actually pay. ${ }^{2}$ The transportation economist will argue 298 that the sum of the change in consumers' and producers' 299 surplus is the appropriate measure of benefit to compare 300 before and after a widened road, land development, or 301 other change in policy or infrastructure. An economist 302 would recognize each trip between a specific origin and 303 destination at a given time by a given mode for a given 304 purpose, as a distinct market, with its own demand 305 curve. The consumer's surplus is measured in each 306 market with and without the change, recognizing that 307 the number of trips in that market before the change 308 may be higher or lower than the number of trips after 309 the change. The price is the money and time (combined 310 into a generalized cost) required to consume a trip in a 311 particular market. If more people are traveling at the 312 same price, or the same number at a reduced price, or 313 some combination of the two, this is deemed a benefit. 314 This measure is summed across all markets. For any 315 given change, some markets may experience an increase 316 in benefit, others a decrease, and the total may or may 317 not be positive.

318 Fig. 1 shows conceptually how consumers' surplus is 319 calculated within a single transportation market. This 320 illustrates two networks. Network 2 is a net improve321 ment on network 1, hence the same number of trips can 322 be accommodated at a lower cost (or more trips for the 323 same cost). The consumers' surplus for network 1 is 324 represented as area $a-b-e$ and for network 2 as area $a-$ $325 b-c-d-e$. The difference, or change in consumers' surplus 326 is the area $b-c-d-e$. In practice, point $a$ is unknown, so 327 the change in consumers' surplus between two scenarios 328 or networks is more useful than the absolute value of the 329 consumers' surplus.

330 The numerous transportation markets are coupled, 331 that is the demand in one affects the supply character332 istics of another. Thus, a reduction in cost in one market 333 will increase the demand in that market. That demand 334 will use links shared by other markets, where the supply 335 was not expanded. Moreover an increase in demand in 336 some markets will increase costs and decrease trips in 337 others. A direct benefit accrues to a market where the 338 improved link is used or the improved link is at least a 339 partial substitute for a link that is used. In this frame340 work, with variable demand, many markets that do not 341 receive the benefit directly will receive a net loss of 342 transportation welfare.

343 The elasticity of demand is generally known near 344 existing price points. In the areas beyond the range of

\footnotetext{
${ }^{2}$ Similarly, Producers' surplus (or profit) is the difference between the cost of production and the price of sale; but for goods that are unpriced, e.g. most roads, there is no producer's surplus.
}

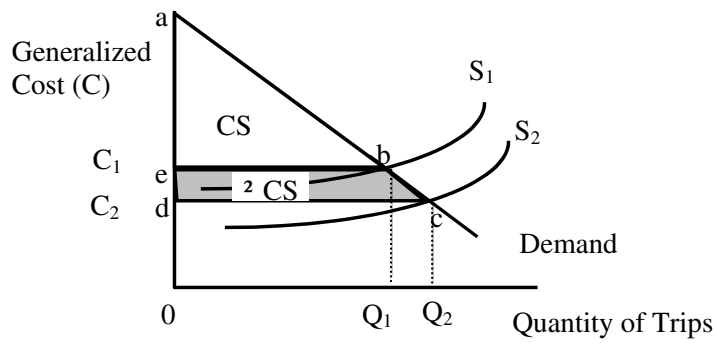

Fig. 1. Consumers' surplus for networks (1) and (2).

our experience, demand is not known well. This is 345 acceptable in the case of the shifts in the supply curve 346 (e.g. adding a new link), when the unknown areas do not 347 enter the measurement. However, with a shift of the 348 demand curve, the whole range of demand must be 349 known to achieve an accurate measurement. 350

With a consumers' surplus measure, the total change 351 in surplus over all markets needs to be compared with 352 the total costs of the project. In economic analysis, if 353 total benefits exceed total costs, the project is worth 354 doing.

Approximating demand as a straight line function, 356 then the following "rule of $1 / 2$ " describes the net user 357 benefit (change in consumers' surplus) ( $\triangle \mathrm{CS}$ ) in a single 358 market (Neuberger, 1971):

$\Delta \mathrm{CS}=0.5\left(Q_{\text {off }}+Q_{\text {on }}\right)\left(\tau_{\text {off }}-\tau_{\text {on }}\right)$

where $Q_{\text {on }}, Q_{\text {off }}$ flows when the ramp meters are on, off 361 respectively. $\tau_{\text {on }}, \tau_{\text {off }}$ travel times when the ramp meters 362 are on, off respectively.

\subsection{Application}

If the travel time when the ramp meters are switched 365 off is greater, then there is a gain of consumer surplus 366 with metering. Using the same afternoon peak period 367 data as was used above in the comparison of mobility, 368 the change in consumers' surplus is measured. On TH- 369 169 , the changes in consumers' surplus for each indi- 370 vidual segment are summed to get a benefit from 371 metering of 3531 vehicle hours. The loss in consumers' 372 surplus on ramps with metering is found to be 639373 vehicle hours. As expected, ramp meters significantly 374 reduce the productivity and consumers' surplus of the 375 ramps. The change in consumers' surplus of the system 376 with ramp metering is overall positive, the ramp meters 377 benefit the freeway segments more than they hurt the 378 ramp segments, so an overall positive change in con- 379 sumers' surplus of 2893 vehicle hours is recorded. On I- 380 94, the net increase in the consumers' surplus of the 381 whole system (including freeways and ramps) due to 382 metering is 481 vehicle hours. 
384

385

386

387

388

389

390

391

392

393

394

395

396

397

398

399

400

401

402

403

404

405

406

407

408

409

410

411

412

413

414

415

416

417

418

419

420

421

422

423

424

425

\section{Productivity ${ }^{3}$}

\subsection{Definition}

In determining whether to build a project, select a policy, implement a system, or provide a service, it is possible, with the help of many assumptions, to estimate the net present value of the future stream of profit or welfare with a cost/benefit analysis. But because of the assumptions required, benefit/cost analysis may not be sufficient to manage a complex system such as a transportation network on a day-to-day basis. There is a desire to monitor the transportation network on multiple dimensions, to understand how well it is performing (and how accurate were previous projections), and to steer future decisions. Metrics might assess how efficiently labor or capital is employed (to determine where future labor or capital should be employed). They might consider market share against competitors, the state of complementary services (for instance, access to transit or parking in the case of a transit system) or the satisfaction of customers and vendors (to gauge future market share and the price and quality of inputs).

Productivity is simply a measure of output divided by input. The larger this ratio, the more productive is the system. The key to measuring productivity is determining the outputs and inputs. Beginning with the inputs, we have, broadly, capital and labor. Labor includes all the human time required to produce a service. So when considering the productivity of transit service, labor inputs comprise the employees of the transit agency, including bus drivers, mechanics, managers, and accountants among others. (And when considering passenger car travel, the driver's time must be included as well.) Capital includes all the buildings and equipment needed to operate the service (buses, garages, offices, computers, etc.). Capital may include land and energy, though those are often separated. While labor may go into each of the capital components, to the agency it is viewed as capital (the labor required to build the bus is considered in the labor productivity of the manufacturer of the bus, but not the operator). Labor productivity $\left(P_{\mathrm{L}}\right)$ can be measured by dividing the output measure $(O)$ with hours of labor input $(H)$. Simi-

\footnotetext{
${ }^{3}$ The question of what is productivity in transportation has several interpretations. One line of research, not followed here, beginning with research by Aschauer (1989) and continuing through Boarnet (in press) and Nadiri and Theofanis (1996) examines how transportation investment affects the economy at large. These papers tend to treat transportation (or highways) as a black box, and make no distinctions between different kinds of transportation investment. The input is state or national investment in transportation, and output is gross domestic product. While this research provides useful rhetorical tools (transportation investments provide an $\mathrm{X} \%$ return, compared with $\mathrm{Y} \%$ for other investments) important for large budget debates, it provides no assistance in actually making management decisions.
}

larly, capital productivity $\left(P_{\mathrm{K}}\right)$ can be defined as the 426 output measure divided by the capital $(K)$ in money 427 terms that is required to produce that output. Capital is 428 somewhat trickier than labor in that capital is often a 429 stock, while output and labor are flows. For example, if 430 it costs one million dollars to build a road section with a 431 multi-year life, we cannot measure the productivity of 432 capital as simply annual output divided by that one 433 million dollars. Rather, that stock needs to be converted 434 to a flow, as if the highway department were renting the 435 road. This conversion depends on the interest rate and 436 the life of the facility.

In freight, output is typically measured by ton-km 438 shipped, input would be the hours of labor and 439 machinery employed. In passenger travel, output may be 440 person kilometers traveled. So improvements that in- 441 crease the number of ton- $\mathrm{km}$ or person- $\mathrm{km}$ that can be 442 transported with the same resources (in the same period 443 of time) increase productivity. Four basic partial pro- 444 ductivity measures for transportation are given in Table 445 4.

Looking at either the productivity of labor or capital 447 to the exclusion of the other is insufficient. Some 448 investments can improve labor productivity at the ex- 449 pense of capital productivity. Total factor productivity 450 measures can be used to combine labor and capital 451 productivity. These require weights for each measure 452 (and any submeasures which comprise a measure) pro- 453 portional to the share of that measure in total costs. This 454 issue becomes more complex when examining changes in 455 productivity between time periods, as both inputs and 456 outputs (and thus shares) change.

A good argument can be made that it is not always 458 good to maximize travel, we do not want to increase 459 distance traveled by building circuitous routes for in- 460

Table 4

Productivity measures

\begin{tabular}{ll}
\hline Description & Formula \\
\hline Productivity of public labor $\left(P_{\mathrm{GL}}\right)$ & $P_{\mathrm{GL}}=\frac{\sum_{l} T_{l}}{\sum_{l} H_{l}}$ \\
Productivity of private labor $\left(P_{\mathrm{PL}}\right)$ & $P_{\mathrm{PL}}=\frac{\sum_{l} T_{l}}{\sum_{l} D_{l}}$ \\
Productivity of public capital $\left(P_{\mathrm{GK}}\right)$ & $P_{\mathrm{GK}}=\frac{\sum_{l} T_{l}}{\sum_{l} K_{l}}$ \\
Productivity of private capital $\left(P_{\mathrm{PK}}\right)$ & $P_{\mathrm{PK}}=\frac{\sum_{l} T_{l}}{\sum_{l} V_{l}}$ \\
\hline
\end{tabular}

Where $T=$ Travel on the system in question (person-km or ton-km), $H=$ Hours of labor by employees of the highway agency (including professional drivers), $D=$ Hours of time by the driver and passengers spent on the network in question (excluding professional drivers), $K=$ Dollars of public capital spent (building and maintaining the infrastructure), $V=$ Dollars of private capital spent (the share of the cost of owning and operating a vehicle, exclusive of taxes to pay for public capital for its use on the network in question), 1 denotes links in the set of links $L$ under question. 
Table 5

Productivity measures with and without meters

\begin{tabular}{|c|c|c|c|c|c|c|}
\hline & & \multicolumn{2}{|l|}{ Segment } & \multicolumn{2}{|c|}{ Ramps } & \multirow{2}{*}{$\begin{array}{l}\text { Productivity } \\
(\mathrm{km} / \mathrm{h})\end{array}$} \\
\hline & & VKT & VHT & VKT & VHT & \\
\hline \multirow[t]{2}{*}{ With meters } & ТH169 & 339,822 & 3341 & 3994 & 703 & 85 \\
\hline & I-94 & 539,286 & 5494 & 3785 & 264 & 94 \\
\hline \multirow[t]{2}{*}{ Without meters } & TH169 & 271,388 & 5214 & 3815 & 95 & 52 \\
\hline & I-94 & 523,027 & 5940 & 3819 & 95 & 87 \\
\hline
\end{tabular}

461 stance. Two effects take place when network distance is 462 shortened. First, there is an immediate reduction of ton$463 \mathrm{~km}$. But there is also a shortened travel time, which may 464 induce more economic activity, trips, and thus ton-km. 465 This paradox can be obviated by looking at point-to466 point distance rather than network distance as the 467 baseline.

468 Productivity is not of itself a perfect welfare measure, 469 especially since it only addresses the costs of production, 470 not the demand side. However it is an indicator whose 471 changes tend to indicate whether welfare is increasing or 472 decreasing. As emphasized earlier, other gauges may be 473 required to indicate overall welfare. Furthermore, we 474 have only described the productivity of transportation, 475 not the activity system to which all travel belongs.

$P=\frac{\text { output }}{\text { input }}=\frac{\sum \mathrm{VKT}}{\sum \mathrm{VHT}}=\frac{\sum Q L}{\sum Q \tau}$

487 The ratio of VKT and VHT is measured for each free488 way segment and ramps separately and then combined 489 to obtain the productivity of the system for both the 490 metering-on and metering-off cases. Ramp metering is 491 considered beneficial if the productivity with its presence 492 is higher.

493 Table 5 shows productivity, the vehicle kilometers of 494 travel per vehicle hours of travel on freeway segments 495 and ramps. The freeway segments have productivity of $496102 \mathrm{~km} / \mathrm{h}$ with metering and $52 \mathrm{~km} / \mathrm{h}$ without meters. 497 The net productivity of the ramps themselves is $5.76 \mathrm{~km} /$ $498 \mathrm{~h}$ with meters and (by assumption) $40 \mathrm{~km} / \mathrm{h}$ without 499 meters. Combining freeway segments with ramps gives a 500 system productivity measure. The system productivity 501 improves immensely with ramp metering. In fact the percentage increase in system productivity is $64 \%$. For I- 502 94, Table 5, suggests an increase in the productivity of 503 the system by $8.26 \%$. This compares with a drop in 504 speed using the mobility measures.

505

\section{Accessibility}

\subsection{Definition}

Accessibility is the measure of the ease with which 508 other pieces of land and their associated activities can be 509 reached (Hansen, 1959; Black and Conroy, 1977; Pirie, 510 1981; Morris et al., 1979). Weibull (1980) suggests that 511 accessibility is a measure of an individual's ability to 512 participate in activities in the environment. If a trans- 513 portation or land use change enables someone to reach 514 activities that are more desirable in less time, then the 515 accessibility (and possibly the value of their land) ${ }^{4}$ in- 516 creases. However, because accessibility increases with 517 activity, areas with high accessibility often have high 518 congestion.

There has long been an interest in the gravity model 520 and in related accessibility measures. In analogy with 521 physics, Reilly (1929) formulated a "law of retail grav- 522 itation", and Stewart (1948) formulated early definitions 523 of accessibility. The measure of potential is now called 524 accessibility (Hansen, 1959). Since Hansen's formula- 525 tion, the distance decay factor has been updated to a 526 more comprehensive function of generalized cost. The 527 function is not necessarily linear-a negative exponen- 528 tial, estimated from models of observed spatial interac- 529 tion (such as gravity models), is often used. Geographers 530 define accessibility as suggested in Table 6 (Hanson, 531

\footnotetext{
${ }^{4}$ Hedonic theory suggests that individuals do not purchase goods, but rather the bundle of attributes composing the good. Someone does not buy a house, but rather the qualities of that house: location (accessibility), size, type of construction, appliances, noise from nearby roads, etc. Every house combines the various attributes slightly differently. Hedonic models are used to pull apart these attributes, and develop demand curves for the various attributes (goods or bads). However, these attributes are interrelated, houses with high accessibility will be more expensive, which will lead to more investment in other attributes, leading to better maintenance and more frequent remodeling.
} 
Table 6

Accessibility measures

\begin{tabular}{ll}
\hline Description & Formula \\
\hline $\begin{array}{l}\text { Accessibility }(A) \text { in zone } i \text { depends on the opportunities (e.g. jobs } P \text { ) in zone } j \text { and the transportation cost } \\
\tau_{i j} \text { between them }\end{array} A_{i}=\sum_{j} P_{j} f\left(\tau_{i j}\right)$ \\
$\begin{array}{l}\text { Job-worker ratio }(R) \text { in zone } i \text { at radius } r \text { (in transportation cost) is the Jobs }(P) \text { within radius } r \text { divided } \\
\text { by Workers }(Q) \text { within radius } r\end{array} \quad R_{i}=\frac{\sum_{j=1}^{r} P_{j}}{\sum_{j=1}^{r} Q_{j}}$ \\
Density $(D)$ in zone $i$ is the sum of jobs and workers within radius $r$, divided by the area contained within & $D_{i}=\frac{\sum_{i=1}^{r} P_{i}+Q_{i}}{\pi r^{2}}$ \\
Difference $(\Delta)$ in zone $i$ is the difference between the number of jobs and workers in radius $r$ & $\Delta_{i}=\sum_{i=1}^{r} P_{i}-Q_{i}$ \\
Force $(F)$ between zones $i$ and $j$ is the product of the jobs $(P)$ in zone $j$ and the workers $(Q)$ in zone $i$ and a & $F_{i j}=Q_{i} P_{j} f\left(\tau_{i j}\right)$ \\
function of the transportation cost $\tau_{i j}$ between them & \\
\hline
\end{tabular}

532 1986). Some other measures relating jobs and workers 533 (or more generically productions and attractions) are 534 also described in Table 6. Accessibility is illustrated in 535 Fig. 2, where the propensity is the willingness to travel a 536 certain distance (the longer the distance/time, the less 537 willing you are to travel), the job supply is the cumu538 lative number of jobs available (which increases with 539 distance/time over which you are searching), and the 540 actual distribution of trips is a product of those two 541 factors.

542 If one takes jobs as supply, and workers as demand, 543 there are many ways to inter-relate the two measures. 544 Force (used as an accessibility measure in the early lit545 erature), described in Table 6, is analogous to the sum of 546 the area formed by the product of supply and demand. 547 The difference $(\Delta)$ between jobs and workers can be 548 viewed as the surplus or deficit in workers at a given 549 travel time away from a point. If for short distances from an individual's house, there is a surplus of jobs, 550 that individual will have a shorter than average com- 551 mute, while if there is a surplus of houses, there will be a 552 longer than average commute (Levinson, 1998). Taking 553 a simple job-worker ratio $(R)$ over some small subre- 554 gional geography (Cervero, 1989, 1996) is clearly a 555 misleading indicator (Giuliano and Small, 1993; Levin- 556 son, 1998). Nevertheless, it may be useful to compare 557 the relative distributions of jobs and housing without 558 falling into a geography trap. A more sophisticated 559 measure would compute the accessibility to jobs and to 560 workers at a point, and take the ratio of these two 561 accessibility measures. It should be noted that accessi- 562 bility to housing varies much less than accessibility to 563 jobs. The sum of supply and demand, jobs and workers, 564 can be taken as a net measure of activity in an area, or 565 after dividing by area, as a measure of density. $\quad 566$

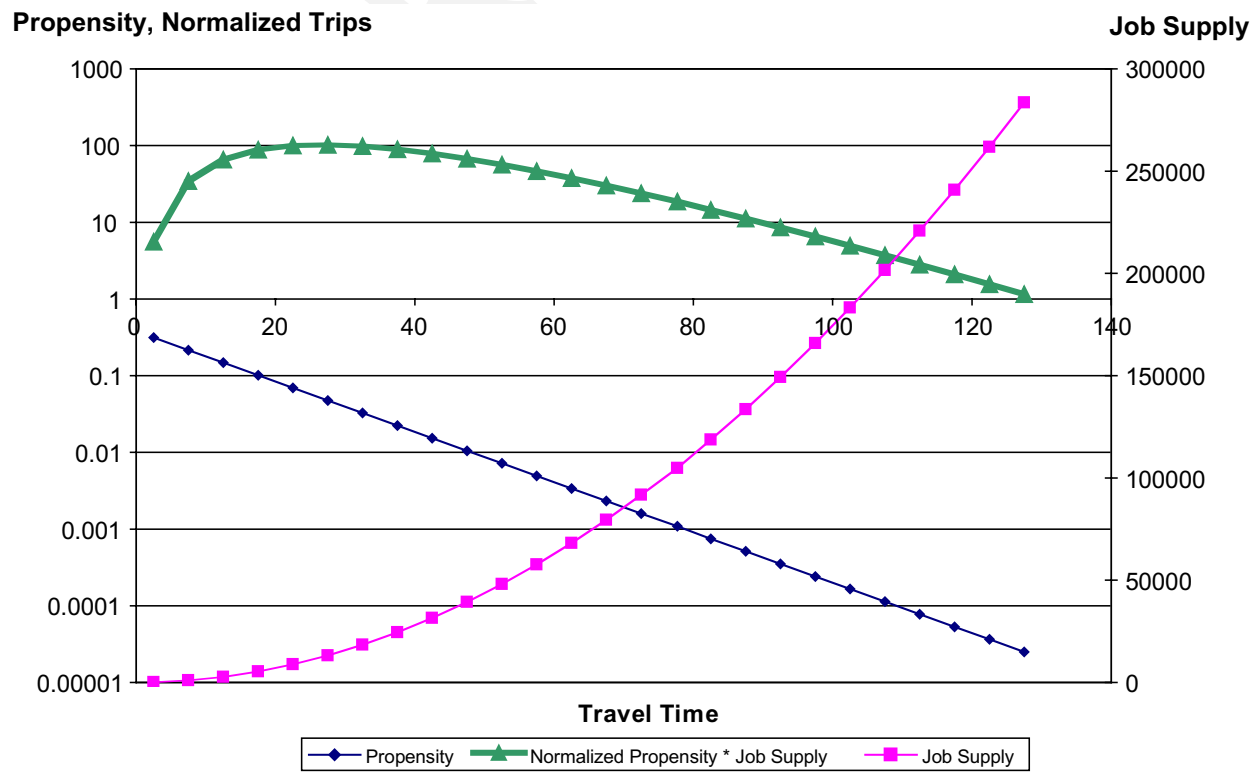

Fig. 2. Accessibility. 
Table 7

Accessibility measures with and without meters

\begin{tabular}{|c|c|c|c|c|c|c|}
\hline \multirow[t]{2}{*}{ Model } & \multicolumn{3}{|l|}{ TH169 } & \multicolumn{3}{|l|}{ I-94 } \\
\hline & With meters & Without meters & $\%$ Change & With meters & Without meters & $\%$ Change \\
\hline$f\left(\tau_{i j}\right)=1 / t_{i j}^{2}$ & 2.9 & 2.5 & 16 & 12.5 & 8.5 & 46 \\
\hline$f\left(\tau_{i j}\right)=\mathrm{e}^{-0.00189 t_{i j}}$ & 58,932 & 34,502 & 71 & 42,977 & 43,597 & -1.4 \\
\hline$f\left(\tau_{i j}\right)=\mathrm{e}^{-0.08 t_{i j}}$ & 93.2 & 63.772 & 46 & 822.5 & 456.9 & 80 \\
\hline
\end{tabular}

\subsection{Application}

Three different functions of travel time are used; these are described in Table 7. Freeway accessibility is computed both with and without ramp metering as in Table 6 (top row), where $P_{j}$, the opportunities at off-ramp $j$, is measured using exit volumes and the travel cost, $\tau_{i j}$ is just the travel time between on-ramp $i$ and off-ramp $j$.

Three different accessibility models were applied to TH169. The first is a classic gravity model, the second a model estimated for freeways in the Twin Cities by the author, and the third from a regional gravity model estimated for Washington DC (Levinson and Kumar, 1995). For all three cases on TH-169 accessibility increases with ramp metering, as shown in Table 7 . However, there may be accessibility functions for which this is not the case. The accessibility measures for I-94 are also shown in Table 7. Unlike TH-169, but consistent with our mobility measures, these results are mixed. In one of the three cases, accessibility falls with metering.

\section{6. Travelers: subjectivity and equity}

588 A first criticism concerns the measure of transporta589 tion rather than activities as the base for the MOE. A 590 transportation or land use change that enabled a person 591 to reduce the total number of trips made might be seen 592 as a net loss from a narrow transportation productivity 593 or consumers' surplus measure with trips or person-km 594 traveled as the output measure, or a mobility measure 595 that looked at throughput However if the reduction is 596 because of trip chaining, performing the same number of 597 activities with less travel, the individual may be better 598 off. This argues for a broader measure of utility of the 599 entire activity system rather than simply the demand of 600 the transportation system. Of course, this also requires 601 entirely new measurement methods.

602 A second criticism is of the aggregation error in603 volved. Supply and demand curves, and consequently 604 accessibility and consumers' surplus measurements, 605 implicitly assume mass produced identical commodities. 606 If the markets are defined coarsely (large zones, few 607 purposes, few or no time slices), the assumption of 608 homogeneity within markets fails. On the other hand, if each individual trip were its own market, supply and 609 demand curves are no longer measures of quantity of 610 exchange, but rather its probability. While the number 611 of coarse markets was large, the number of potential 612 individual transactions is huge. This clearly makes an 613 accurate measurement of consumers' surplus difficult. 614

A third criticism is the absence of the consideration of 615 choice and the existence of non-user benefits in the 616 MOE. If transportation is a derived demand, the activ- 617 ities at the end are what count. It can be argued that not 618 only the activities pursued, but also the ones not pur- 619 sued, should be considered in evaluation.

Further these measures incompletely capture the 621 costs and benefits associated with spillovers and exter- 622 nalities. Transportation change enables/requires reor- 623 ganization of processes, which provides benefits/costs 624 outside the transportation sector. Particularly in the case 625 of unpriced transportation, it is very difficult to capture 626 these spillover benefits or external costs and internalize 627 them within the transportation sector. 628

The general focus on systematic efficiency ignores 629 equity effects on individual welfare from a change in the 630 transportation-land use system. While at one level 631 everyone understands that change creates winners and 632 losers, at another, only the aggregate net gain is gener- 633 ally considered. Much cost benefit analysis is based on 634 the Kaldor-Hicks or potential Pareto improvement test. 635 This says that a change is acceptable provided the losers 636 could be compensated from the gains of the winners, 637 whether or not they actually are. But this test may not 638 command social acceptance, particularly from the los- 639 ers. Thus, economic decisions are devolved into the 640 political and legal arenas, where voices are not neces- 641 sarily weighted equally. Diffuse winners may not expend 642 energy to defeat concentrated losers, despite an overall 643 "net gain." By the economic calculus, society is worse 644 off. Can this be anticipated and avoided?

It needs to be recognized that winners and losers are 646 created all of the time. The simplest changes to the 647 transportation network create winners and losers, not 648 just due to the taking of land, or the creation of pollu- 649 tion effects, but even mobility reductions from the rel- 650 atively narrow transportation perspective. It is essential 651 to develop MOE (both of efficiency and equity) that 652 identify these issues before they become political prob- 653 lem. Unfortunately, no single MOE will capture every- 654 
655 thing. Complexity implies uncertainty, so any one 656 measure will be incomplete. Yet, the alternative of not 657 doing the analysis is also unacceptable. Explicit con658 sideration of equity and the distribution of winners and 659 losers will highlight potential problems before they 660 manifest themselves.

661 Just as Einstein noted that the point of view of the 662 observer shaped the measurement of time, point of view 663 also affects the perception of time as a measure of 664 transportation level of service. Moving towards trip665 based measures will more closely align with how users 666 experience travel. For instance estimating the travel time 667 of individual trips, and looking at the distribution of 668 changes in travel times resulting from changes to the 669 transportation-land use system will allow even sys670 tematic and objective measures to get at the same per671 ceptions that are subjectively experienced. However 672 more research is needed into how individuals perceive 673 travel, and how they value or weight components of the 674 travel experience.

\section{Conclusions}

676 This paper identified four major classes of efficiency 677 measures: mobility, utility, productivity, and accessibil678 ity. Each has strengths and weaknesses, justifying its 679 use, but not its exclusive use, as a gauge of the perfor680 mance of the transportation system. Like the blind men 681 examining the elephant, there is no single perspective 682 that can be accurately measured and will correctly de683 scribe the system. In fact, looking at the Twin Cities 684 Ramp Meter shut down data shows that while some685 times the measures align with each other and all give a 686 clear message (ramp meters were efficient on TH-169), in 687 other cases the results are contradictory (ramp meters 688 may or may not have been efficient on I-94).

689 Mobility is the traditional measure used by engineers, 690 and has the advantage of ease of measurement. Travel 691 time is a useful measure that aligns with user experience, 692 but users care about trips rather than simply links. 693 There is a reason these measures are used by transpor694 tation engineers, the data is easy to relatively easy to 695 collect. It is most appropriate to use mobility when 696 looking at short-run, small-scale system change, espe697 cially traffic operational improvements. It can be 698 thought of as the most tactical measure. In general it 699 should track productivity and consumers' surplus, but 700 the results may differ if the two situations being com701 pared are very similar. Mobility measures may also be 702 useful for filtering analysis. Since mobility is easy to 703 measure, ranking sites to study more intensively with 704 e.g., a measured volume/capacity ratio, and then doing a 705 more thorough analysis is a cost-effective approach 706 when the cost of analysis is significant.
Productivity is important to examine when managing 707 the system, and especially for measuring the efficiency of 708 the supply-side, but again it is not experientially based. 709 Productivity are appropriate in a somewhat larger scale 710 than mobility, but are still relatively short-term mea- 711 sures. It may be appropriate to look at small-scale 712 investments that should not have system-wide reper- 713 cussions. It is tactical, but not as short-term as mobility. 714

Utility might match travelers the best, if only it could 715 be measured. Consumers' surplus is a useful system 716 measure, but the aggregation of the measure means that 717 it does not match any particular user's experience. 718 Transportation consumers' surplus is appropriate for 719 medium-term evaluation of major investments that have 720 relatively minimal effects on the distribution of land 721 uses. This is inherently a more strategic measure than 722 productivity, but as defined here, ignores the value of 723 opportunities that accessibility aims to measure. $\quad 724$

Accessibility provides an overview relationship of 725 transportation, activities, and land uses, but is hard to 726 explain and not easily operationalized into policy. 727 Accessibility is critical to look at the long-term impacts 728 of major investments and the impacts of land use reg- 729 ulatory changes. This is the most strategic measure. $\quad 730$

A key difficulty is that subjective perspectives of 731 travelers contrast with the objective views of profes- 732 sionals. There is no single "subjective perspective of 733 travelers," as different travelers will by definition have 734 different perceptions. Taking the driver's eye (passen- 735 ger's eye, pedestrian's eye) point-of-view (looking at 736 trips for instance, or potential destinations) rather than 737 a bird's eye assessment is a start. Defining the specific 738 measures may not be too difficult, (e.g. travel time is one 739 obvious consideration), although weighting those mea- 740 sures requires empirical work (not all time is created 741 equal from the point-of-view of the travelers, a large 742 body of research suggests that waiting time is more 743 onerous than in-vehicle time). But only by considering 744 that subjective perspective as an input can those deci- 745 sions be implemented in a political environment where 746 everyone has a different viewpoint and set of values.

\section{Uncited references}

Garber and Lester (1999), Levinson (2000).

\section{Acknowledgements}

The author would like to thank research assistants 751 Pavithra Kandadai Parthasarathi, Seshasai Kanchi, Lei 752 Zhang, Atif Sheikh, and Shantanu Das who contributed 753 to this report. The author thanks Betty Deakin for 754 comments on an earlier draft of this paper. This paper 755 draws in part on work done while the author was at the 756 
757 Montgomery County, Maryland Planning Department.

758 The author would also like to thank the Minnesota

759 Department of Transportation who funded this research

760 through the project Measuring the Equity and Efficiency

761 of Ramp Meters. All opinions and errors in this report

762 remain those of the author.

\section{References}

Aschauer, D., 1989. Is public expenditure productive? Journal of Monetary Economy Market 23 (2), 177-200.

Black, J., Conroy, M., 1977. Accessibility measures and the social evaluation of urban structure. Environment and Planning A 9, 1013-1031.

Boarnet, M. Road infrastructure, economic productivity, and the need for highway finance reform. Public Works Management and Policy, in press.

Caltrans, 1998. California Transportation Plan: Transportation System Performance Measures.

Cervero, R., 1989. Jobs-housing balance and regional mobility. Journal of the American Planning Association 55 (2), 136-150.

Cervero, R., 1996. Jobs-housing balance revisited. Journal of the American Planning Association 62 (4), 492-511.

Coyle, J.J., Edward, J.B., Robert, A.N., 2000. Transportation 5e. South-western College Publishing, Cincinnati, $\mathrm{OH}$.

Garber, N., Lester, H., 1999. Traffic and Highway Engineering: Revised Second Edition. Brooks/Cole Publishing Company, Pacific Grove, CA.

Giuliano, G., Small, K., 1993. Is the journey to work explained by urban structure? Urban Studies 30 (9), 1485-1500.

Handy, S., 2002. Accessibility vs. mobility-enhancing strategies for addressing automobile dependence. In: The US Prepared for the European Conference of Ministers of Transport, May 2002.

Hansen, W., 1959. How accessibility shapes land use. Journal of the American Institute of Planners, 73-76.

Hanson, S., 1995. Geography of Urban Transportation, second ed. Guilford Press, New York.

Kaplan, R.S., Norton, D.P., 1996. The Balanced Scorecard: Translating Strategy into Action. Harvard Business School Press, Boston.

Levinson, D., 1998. Accessibility and the journey to work. Journal of Transport Geography 6 (1), 11-21.
Levinson, D., 2000. Monitoring infrastructure capacity. In: Land Market Monitoring for Smart Urban Growth. Proceedings of Conference on Land Supply and Infrastructure Capacity Monitoring for Smart Urban Growth. Sponsored by the Lincoln Institute for Land Policy and the US Department of Housing and Urban Development March 30 to April 1, 2000, Cambridge, Massachusetts, pp. 165-181.

Levinson, D., 2002. Identifying winners and losers in transportation. Transportation Research Record: Journal of the Transportation Research Board 1812, 179-185.

Levinson, D., Kumar, A., 1995. A multi-modal trip distribution model. Transportation Research Record 1466, 124-131.

Levinson, D., Zhang, L., Das, S., Sheikh, A., 2004. Ramp meters. In: Gillen, D., Levinson, D. (Eds.), Assessing the Benefits and Costs of Ramp Metering. Kluwer Publishers.

Morris, J.M., Dumble, P.L., Wigan, M.R., 1979. Accessibility indicators for transport planning. Transportation Research 13A (4), 91109.

Nadiri, M.I., Theofanis, P.M., 1996. Contribution of Highway Capital to Industry and National Productivity Growth. Federal Highway Administration. Available from <http://www.fhwa.dot.gov/reports/growth.pdf>.

Neuberger, H., 1971. User benefit in the evaluation of transport and land use plans. Journal of Transportation Economics and Policy, 52-75.

Pickrell, S., 1999. Multimodal Transportation: Development of a Performance-Based Planning Process National Cooperative Highway Research Program Project 8-32(2)A, FY 1994 (Cambridge Systematics).

Pirie, G.H., 1981. The possibility and potential of public policy on accessibility. Transportation Research 15A (5), 377-381.

Reilly, W.J., 1929. Methods for the Study of Retail Relationships, University of Texas Bulletin No 2944, Nov. 1929.

Small, K., 1999. Project evaluation. In: Gomez, Ibanez, Jose, Tye, W.B., Winston, C. (Eds.), Essays in Transportation Economics and Policy: A Handbook in Honor of John R. Meyer.

Stewart, J.Q., 1948. Demographic gravitation: evidence and application. Sociometry XI, 31-58.

Texas Transportation Institute, 2000. The 1999 Annual Urban Mobility Study. Available from <http://mobility.tamu.edu/ $>$.

Transportation Research Board, 2000. Special Report 209 Highway Capacity Manual. Washington DC. 